\title{
Dynamics of the transition process towards partnership thinking in centralized public procurement
}

\author{
Outi Keränen \\ University of Oulu, Oulu Business School, P.O. BOX 4600, FI-90014, Finland \\ E-mail address: outi.keranen@oulu.fi
}

\begin{abstract}
This research paper seeks to increase the knowledge of the transition process from transactional arm's length tendering towards partnership thinking in centralized public procurement. In centralized public procurement, the professional public purchaser forms a triadic partnership relationship with the public unit managing the procurement implementation and the private organization. A triadic partnership relationship in a home nursing procurement setting is investigated to further the understanding of the relationship dynamics related to the transitioning of public and private actors towards partnership thinking. The research shows how transactional procurement logic hinders the transition to partnering by establishing challenges for initiating and nurturing public-private partnerships (PPPs) and how partnership thinking changes this procurement logic. It illustrates the transactional procurement logic of single actor and the logic underlying the relationship of two actors to engender and intensify the problems of triad in the centralized public procurement process and vice versa; that is, a shared understanding from jointly agreed procurement goals between two actors is identified as promoting triadic partnering. Managerial implications are given for those public and private organizations engaging in PPPs and seeking to understand the ways of managing them in the context of centralized public procurement, particularly during the transition towards partnership thinking.
\end{abstract}

Keywords: Public-private partnership; Relationship dynamics; Triadic relationship; Centralized public procurement; Home nursing 


\section{Introduction}

The ineffectiveness of a rational and legalistic public procurement system to deliver public services effectively with limited budgets (Hood, 1991; Rees \& Gardner, 2003) has promoted public authorities to learn from private markets and thus renew their procurement practices and management models (Arlbjørn \& Freytag, 2012; Essig \& Batran, 2005). These procurement reforms show the modernization of public management (Guzmán \& Sierra, 2012), which increasingly relies on reciprocally rewarding and trusting partnership relationships with private organizations (Lawther \& Martin, 2005). In the literature, different collaborative public-private efforts are referred to as public-private partnerships (PPPs) (Roehrich, Lewis, \& George, 2014; Schaeffer \& Loveridge, 2002) that are institutional arrangements between public and private organizations (Hodge \& Greve, 2007) to reach a shared goal of delivering goods and services to the public (Jamali, 2004).

The emergent interest in PPPs has drawn scholars to examine what promotes (e.g., Jamali, 2004; Li, Akintoye, Edwards, \& Hardcastle, 2005; Zou, Kumaraswamy, Chung, \& Wong, 2014) or hinders PPPs (e.g., Erridge \& Greer, 2000; Jamali, 2004; Klijn \& Teisman, 2003) and to investigate how partnering might advantage (e.g., Barlow, Roehrich, \& Wright, 2013; Erridge \& Greer, 2002) or disadvantage public procurement (e.g., Roehrich \& Caldwell, 2012; Zheng, Roehrich, \& Lewis, 2008). If properly managed, PPPs facilitate the delivery of high quality public services by expanding interorganizational collaboration and resource exchange, mitigating risks and promoting innovation (Erridge \& Greer, 2002; Kwak, Chih, \& Ibbs, 2009). Nevertheless, PPPs are different from relationships between private firms (Bovaird, 2006); that is, their development is governed by the regulatory framework and is influenced by the public procurement culture (Erridge \& Greer, 2000), which tend to stress transactional exchange and arm's length relationships (Lian \& Laing, 2004). This is argued to generate problems of instability and inadequate relationship quality (Zou et al., 2014) that emerge when public organizations merely react to the changes in markets rather than proactively attempt to initiate trustful partnership relationships with private organizations (Smyth \& Edkins, 2007). Therefore, public and private actors must now learn how to implement procurements more collaboratively instead of using traditional transactional arm's length tendering.

Partnering in public procurement differs from traditional tendering (Smith \& Wohlstetter, 2006) by changing the way of how public and private actors interact (Lawther \& Martin, 2005) and how their long-term relationships are governed (Zheng et al., 2008). 
Regardless of these changes that partnership thinking is argued to engender for public-private collaboration, little research has examined the transition process from transactional arm's length procurement towards partnership thinking in a public setting (Hartmann, Roehrich, Frederiksen, \& Davies, 2014; Schaeffer \& Loveridge, 2002). Furthermore, although delivering public goods and services requires nowadays collaboration with the network of actors (Bovaird, 2006), the transitioning literature has primarily involved dyadic settings and left the influence of third actors and surrounding relationship dynamics on the process underresearched.

The purpose of this research paper is to increase understanding of the transition process of public and private actors, moving from transactional arm's length tendering towards partnership thinking, particularly in centralized public procurement. In centralized public procurement, three actors - the professional public purchaser, the public unit managing the procurement implementation and the private organization - form a triadic partnership relationship by collaborating repeatedly to deliver public services. The interaction in triads is highly interlinked (Caplow, 1956) and the third actor tends to influence the other two actors, either by positively keeping the triad together or negatively disturbing the relationship (Simmel, 1950: 135). Furthermore, the roles of the actors and the relationships between them change during the procurement process (Li \& Choi, 2009). Triads are thus dynamic (Gutek, Groth, \& Cherry, 2002) and by incorporating a third actor into the relationship setting the triad may further the understanding of the relationship dynamics influencing the transition process towards partnership thinking in public procurement and contribute to the knowledge of this transitioning. The purpose of this paper is to emphasize the subsequent research question, which seeks to give managerial insights for actors looking to build stronger PPP relationships:

How is the transition process of public and private actors towards partnership thinking influenced by the relationship dynamics in the triadic setting?

The research question is supplemented by two sub-questions:

What are the challenges that hinder the transitioning towards partnership thinking in public procurement?

How is partnering promoted during the transitioning towards partnership thinking in the triad? 
The remainder of this paper reviews the literature on different forms of relationships between public and private actors and the mechanisms underlying them. Then, the research related to the dynamics of triadic relationships is introduced and brought into the context of centralized public procurement to theoretically understand the relationship dynamics influencing the transition process towards partnership thinking in centralized public procurement. Thereafter, the research methods are described and the key findings from centralized home nursing procurement presented. In the last chapters, the theoretical and managerial implications are discussed, the limitations assessed, and suggestions for future research proposed.

\section{Transitioning towards partnership thinking in public procurement}

Public procurement has traditionally applied the transactional paradigm where savings and effectiveness are reached through competitive tendering (Lian \& Laing, 2004). This paradigm is promoted by the regulations and principles surrounding public procurement (Erridge \& Greer, 2000), requiring public purchasers to strive for delivering better services to the public for fewer costs and stress fairness and transparency of their contracting practices by using designated procurement procedures (Erridge \& McIlroy, 2002; Rainey \& Bozeman, 2000). In traditional public tendering, the purchaser determines the requirements and manages primarily suppliers meeting these requirements. Therefore, their exchange is transactional and relationships are characterized by short-term agreements and arm's length negotiations. (Erridge \& McIlroy, 2002.) Nevertheless, this type of competitiveness tends to increase the length and formality of the procurement process (Erridge \& Greer, 2002; Rainey \& Bozeman, 2000), which establish transaction costs and diminish the freedom of public organizations to render procurement decisions, while the arm's length relationships limit their opportunity to estimate the risks and other uncertainties related to procurement agreements (Erridge \& McIlroy, 2002).

Research has shown the paradigm shift within public management. This has led to the development of new kinds of public strategies and practices that promote the change from transactional arm's length relationships to building reciprocally rewarding and trustworthy partnership relationships with private organizations (Lawther \& Martin, 2005). PPPs are recognized to improve public procurement (Kumaraswamy, Ling, Anvuur, \& Rahman, 2007); they reinforce contractual ties (Brown, Potoski, \& Van Slyke, 2007) and foster interorganizational collaboration (Smyth \& Edkins, 2007) by establishing trust and knowledge exchange between public and private actors (Erridge \& Greer, 2002). 
Scholars suggest that the transition process towards partnership thinking rests on different levels and depth of interaction, with the process being less formal and supplemented by informal ties between the members of exchanging organizations (Lian \& Laing, 2004). The coordination between relationship parties thus increases in partnering (Erridge \& McIlroy, 2002; Schaeffer \& Loveridge, 2002), particularly through informal relational governing mechanisms, like trust (Zheng et al., 2008). The degree of coordination, in turn, illustrates the cooperation of relationship parties (Metcalf, Frear, \& Krishnan, 1992) and it influences the realization of agreed rules and norms, which are required to reach shared goals (Anderson \& Narus, 1990). Partnering thus influences actors' collaborative attitude; that is, willingness to resolve problems and commitment in the relationship (Campbell, 1985). In a public setting, determining jointly the relationship goals (Jamali, 2004; Lawther \& Martin, 2005) and an unambiguous, though resilient coordination of responsibilities and roles, and forming shared working practices (Jacobson \& Choi, 2008; Jamali, 2004) are find important in creating commitment (Jacobson \& Choi, 2008; Zou et al., 2014).

The degree of cooperation and coordination are reliant on information exchange (Wang \& Bunn, 2004). That is, partnering changes knowledge sharing routines from top down to the two-way flow of information, which supports the establishment of shared understanding and determination of joint procurement goals, rules and norms (Jamali, 2004; Schaeffer \& Loveridge, 2002). Increased interaction and information exchange are further suggested to promote the development of trust and reciprocity, which are likely to work as informal governing mechanisms in partnerships (Erridge \& Greer, 2002). In partnering, particularly interpersonal relationships are thus important; they facilitate problem solving, surpassing the barriers of information exchange and building mutual trust (Metcalf et al., 1992).

Regardless of that the term 'PPP' has initially related to the privatization of public services, it is admitted that there is no single PPP model and that PPPs refer to a wide range of relationships between public and private organizations (Jamali, 2004). PPPs thus differ by their origin, content, form and depth and they diverge from 'weak' and insubstantial to 'strong' and meaningful partnership relations (Smith \& Wohlstetter, 2006). In the categorization of Schaeffer and Loveridge (2002), for example, the leader-follower relationship is the most implicit form of collaboration between public and private organizations, although its coordination rests on formal agreements. This relationship reminds somewhat transactional arm's length relationships, characterized by infrequent information exchange and remote relational norms (Wang \& Bunn, 2004). In this type of 
relationship, the information sharing relates either purely to tendering or it is guided by the public purchaser and thus the relationship remains distant (Erridge \& McIlroy, 2002).

If relationship parties find being better off after transaction, unambiguous and extensive exchange relationships (Schaeffer \& Loveridge, 2002) and different types of resource exchange collaboration activities (McGuire, 2000) are recognized to emerge. In these relationships, partners must learn how to work together (Bovaird, 2006) by establishing mechanisms for coordination and relying more on face-to-face negotiations (Schaeffer \& Loveridge, 2002). Therefore, exchange relationships resemble recurrent relationships (Ring \& Van de Ven, 1992) in which actors collaborate to implement repetitive exchange, but the flow of information shared and frequency of this is reliant on the goods and services exchanged (Schaeffer \& Loveridge, 2002; Wang \& Bunn, 2004). The exchange relationships are thus presented to require partners to define specific procurement goals through formal agreements to make sure that they both benefit from the interaction, but the nature of what is exchanged and who is responsible for what is negotiated to identify better ways of delivering the public services (Schaeffer \& Loveridge, 2002). This reminds the form of market relationship that Bovaird (2006) regards as relational contracting that is grounded on trust (Parker \& Hartley, 2003).

Joint ventures (Schaeffer \& Loveridge, 2002), or project-centered collaboration activities (McGuire, 2000), are particular forms of PPPs in which collaboration is strictly coordinated, but joint decision-making between relationship parties is rare. These relationships are formed if participants presume to gain from working together on their shared goals, but otherwise wish to keep their freedom by defining their financial commitments up front (Schaeffer \& Loveridge, 2002; Wang \& Bunn, 2004). In the literature, partnerships (Schaeffer \& Loveridge, 2002), or strategy-making collaboration activities (McGuire, 2000), partnership procurements (Bovaird, 2006) and collaborative relationships (Wang \& Bunn, 2004), are though regarded as the strongest form of relationship between public and private actors. In partnerships, multiple actors collaborate (Erridge \& McIlroy, 2002) and contribute to the partnership by bringing something into it (Bovaird, 2006;

Schaeffer \& Loveridge, 2002). Therefore, the actors share the rewards and decision-making and take the responsibility for the risks of their activities (Schaeffer \& Loveridge, 2002); thus, the coordination of their knowledge exchange is substantial and frequent and their relationship is characterized by trust and high reciprocity (Erridge \& McIlroy, 2002). This type of coordination is recognized to stipulate collaboration through distributed commissioning in which public purchasers permit multiple organizations to determine for 
themselves the priorities between public services (Bovaird, 2006). Wang and Bunn (2004), for their part, distinguish supervisory relationships to exist between public and private organizations if governmental purchasers give private organizations responsibility and freedom to resolve how to reach their requirements.

Regardless of the different relationship forms between public and private actors, public authorities are reproached for lacking expertise to build partnerships (Erridge \& Greer, 2002). Erridge and Greer (2000) suggest that the legal framework and the culture of public organizations generate barriers for interorganizational collaboration and prevent public organizations from initiating partnerships with trust (Smyth \& Edkins, 2007). Reijniers (1994) further grants PPP problems to relate to the organizing and managing of procurement implementation, which is stated to stem from the lack of internal and external stakeholder alignment (Roehrich et al., 2014). Furthermore, it is agreed that different strategic, institutional, organizational and interpersonal differences between the relationship partners might hinder the establishment of shared understanding and thus generate PPP failures (Jamali, 2004; Klijn \& Teisman, 2003).

Altogether, partnership relationships are characterized by change. That is, rather than being static, processes within the relationship and in the surrounding network establish change and dynamics (Holmlund \& Törnroos, 1997). In this research paper, the transition from transactional arm's length tendering to partnership thinking is therefore inherently regarded as dynamic. To understand the dynamics influencing this process, the relationship dynamics in triads, in the context of centralized public procurement, are discussed next.

\section{Dynamic triads in centralized public procurement}

Public procurements are increasingly centralized, which refers to centralizing activities that include the formation of centralized framework agreements for public units and the administration of that agreement (Karjalainen, 2011). In this type of procurement process, professional public purchasers perform contracting by determining whether public services are contractable, examining whether there are private organizations from which to purchase, and then implementing the bidding process (Brown \& Potoski, 2003). Thereafter, the task of monitoring the private partner to determine whether it has fulfilled its responsibilities (Brown $\&$ Potoski, 2003) is decentralized to public units managing the procurement implementation (Karjalainen, 2011). 
Centralization is argued to influence the possibilities of public purchasers to directly control the quality of outsourced services (van Iwaarden \& Van der Valk, 2013), which increases the importance of partnering between the three actors of centralized public procurement. The three actors must interact frequently and learn how to work together to deliver public services, thus engendering a triadic partnership relationship between them (Madhavan, Gnyawali, \& He, 2004; Simmel, 1950; Thibaut \& Kelley, 1959). A triad refers to the relationship of three independent actors that are directly linked to each other by exchange relationships for the purpose of trading goods and services (Tähtinen \& Halinen-Kaila, 1997). Madhavan et al. (2004) characterize triads as "transitive", which implies the direct links between the three actors and makes the collaboration in triads more problematic than in dyads (Holma, Björk, \& Virtanen, 2009). In triads, the interaction between the actors is interlinked (Caplow, 1956); if A interacts with B, it restricts the possibilities of A to interact at the same time with C (Havila, Johanson, \& Thilenius, 2004). The interaction between two actors is thus influenced, mediated and facilitated by their respective interactions with the third actor and the roles they perform in the triad (Havila et al., 2004; Holma et al., 2009). This establishes ongoing change and instability to the relationship structures between three actors (Gutek et al., 2002; Li \& Choi, 2009), thus making the triad challenging from a relationship dynamics perspective. Furthermore, it makes triadic relationships different by their degree of internal cohesiveness and the ability to act as an entity, which permit distinguishing triads either as a group-like triad, a set-of-connected actors, a coalition or hub-driven-strategicnetwork (Vedel, Holma, \& Havila, 2016).

Therefore, triads are dynamic entities embedded in their context. That is, they are initiated, developed and sustained through ongoing interaction processes through which different internal technical, administrative and other types of activities and technological, material, knowledge and intangible resources emerge during procurement processes and link and tie the actors together and establish bonds between them (Halinen \& Tähtinen, 2002; Håkansson \& Snehota, 1995: 26). The development of relationships is further influenced, directly or indirectly, by other organizations and their relations (Anderson, Håkansson, \& Johanson, 1994) and thus it is impossible to investigate the transition process towards partnership thinking in centralized public procurement without probing the way of how individual organizations or their relationships are linked to other organizations and their relations (Holma et al., 2009). Halinen and Tähtinen (2002) suggest that the relationship development is thus influenced by different task, actor, dyad and network-related factors. These factors are either relatively static, underlying and structural factors that increase the 
predisposition of relationship breakage or dramatic and unexpected events that generate changes and tensions in the relationship during its life time, and which thus require attenuating by factors that reinforce the management of the partnership relationship (Halinen \& Tähtinen, 2002).

\section{Research methodology}

The method for this paper is a qualitative single case study. This research design is suitable for creating a thorough understanding of transition process towards partnership thinking in centralized public procurement and researching the interaction between public and private actors engaging in PPPs during this change (Easton, 1995; Halinen \& Törnroos, 2005). The method permits exploring the dynamics that the research phenomenon includes (Eisenhardt, 1989) without separating it from its own context (Yin, 2003: 18).

The transition towards partnership thinking is empirically investigated through the centralized home nursing procurement, which permits learning (Stake, 2005: 451-455) from the non-smooth transition process to partnering and the relationship dynamics influencing this transitioning in the triadic setting. The home nursing procurement introduces the outsourcing of $10 \%$ of Finnish town's home nursing services for a private home nursing provider during the period 1.1.2013-31.12.2015. In this town $\mathrm{X}$ that has 70,000 inhabitants, home nursing embraces health services that are aimed at increasing and retaining 200 inhabitants' ability to function at home.

The procurement was initiated by a public procurement unit specializing in the procurements of public services for the elderly. The procurement unit performed contracting tasks by adhering to the public procurement legislation of the EU (Directive 2004/18/EC ${ }^{1}$ ) during 2012 by organizing a technical dialog ${ }^{2}$ to improve the rigor of their tendering reports and develop a new incentive system. The new incentive system was developed to monitor the performance of the private partner and it required a new kind of partnering during the

\footnotetext{
${ }^{1}$ Directive 2004/18/EC of the European Parliament and of the Council of 31 March 2004 on the coordination of procedures for the award of public works contracts, public supply contracts and public service contracts.

${ }^{2}$ Before launching a procurement procedure, contracting authorities may conduct market consultations with a view to preparing the procurement and informing economic operators of their procurement plans and requirements. For this purpose, contracting authorities may for example seek or accept advice from independent experts or authorities or from market participants. That advice may be used in the planning and conduct of the procurement procedure, provided that such advice does not have the effect of distorting competition and does not result in a violation of the principles of non-discrimination and transparency. (Directive 2014/24/EU).
} 
procurement process. Thereafter, the procurement unit applied an open procedure ${ }^{3}$ to form a service agreement (EUR 1000000) with an initial private home nursing provider for delivering home nursing services to town $X$ from the beginning of 2013. This initiated a home-nursing-related PPP with them, the private service provider and the public home nursing unit managing the procurement implementation. Nevertheless, shortly after starting collaborating, insuperable problems and tensions started to emerge between the three actors, which led the initial private home nursing provider to sacrifice their procurement agreement for a new private service provider that took charge of delivering home nursing services with the existing terms and staff in November 2013. This change initiated a new home nursingrelated PPP between the two public units from town $\mathrm{X}$ and the new private home nursing provider.

The primary data include 11 thematic single and pair interviews (Arksey \& Knight, 1999). The interviewees were primarily selected from the two public units and the new private home nursing organization, where the persons took part of the contracting or procurement implementation stage and thus they had retrospective insights into the timeline of procurement (Table 1). The interviewees also included the town's higher management, who provided insights from the procurement organization and culture, and two private organizations assisting the public procurement unit to prepare their tendering reports. The retrospective data is suitable for process-centered analysis by making it possible to understand how the research phenomenon has developed and why it has developed in this way (Halinen \& Mainela, 2013). The data includes the characteristics of process data by dealing with temporally embedded sequence of eclectic "events", which include multiple levels and units of analysis (Langley, 1999). The interviewing started from the managers of public procurement and public home nursing units that gave information on other important interviewees. This type of snowball sampling (Biernacki \& Waldorf, 1981) was utilized until the findings started to saturate (Guest, Bunce, \& Johnson, 2006) and the interviewees did not propose new interviewees.

\footnotetext{
${ }^{3}$ In open procedures, any interested economic operator may submit a tender in response to a call for competition (Directive 2014/24/EU).
} 
Table 1

The primary data.

\begin{tabular}{|c|c|c|}
\hline Organization & Interviewed informant(s) & Time \& length of the interview \\
\hline Public Procurement Unit & Manager of Public Procurement Unit & October $2014,1 \mathrm{~h} 45 \min ^{\mathrm{a}}$ \\
\hline \multirow[t]{3}{*}{ Public Home Nursing Unit } & Manager of Home Nursing Unit & October $2014,1 \mathrm{~h} 45 \min ^{\mathrm{a}}$ \\
\hline & Service Manager I & November 2014, $50 \mathrm{~min}$ \\
\hline & Service Manager II & December 2014, 1 h 15 min \\
\hline New Private Home & Regional Manager \& Team Leader & November 2011, 1 h $50 \mathrm{~min}$ \\
\hline \multirow[t]{2}{*}{ Nursing Provider } & Sales Analytic & November $2014,1 \mathrm{~h}$ \\
\hline & Chief Executive Officer & $\begin{array}{l}\text { December } 2014,50 \min \& \\
\text { January } 2015,20 \mathrm{~min}\end{array}$ \\
\hline Procurement Expert I & Procurement Manager & October $2014,50 \mathrm{~min}$ \\
\hline Procurement Expert II & Development Manager & November 2014, 1 h 5 min \\
\hline \multirow[t]{2}{*}{ Town X } & Development Manager & October $2014,35 \mathrm{~min}$ \\
\hline & Town Manager & November $2014,50 \mathrm{~min}$ \\
\hline
\end{tabular}

a Pair interview held for the managers of Public Procurement Unit and Public Home Nursing Unit.

The secondary data was utilized to supplement and confirm the primary data (Cowton, 1998) and to gain background information from the home nursing procurement and the characteristics of home nursing markets. This data included information from the web pages of researched organizations that increased the understanding of their activities, and written reports, including request for quotation (RFQ) and the permission for partial outsourcing of two home nursing districts, and newspaper articles that gave further insights for the home nursing procurement process. The newspaper articles were also utilized to confirm the events with the initial private service provider for the sensitivity reasons. In addition, four public procurement-related seminars held by national EU procurement professionals supported the researcher's efforts to generally understand the public procurement regulations of the EU and the framework in which public and private organizations collaborate. The purpose of this data was to increase data triangulation (Denzin, 1978) and thus to increase the trustworthiness of the interpretations made from the interview material (Cowton, 1998).

Abductive logic of reasoning was utilized (Dubois \& Gadde, 2014) to reinforce the ongoing interaction between theory and data. In this paper, the data guided the development of the theoretical framework and the understanding of these theoretical dimensions assisted in the analysis of home nursing procurement. Therefore, the theoretical framework facilitated the empirical analysis, although new findings were allowed to emerge from the data. The researcher began with her empirical analysis inductively by making notes from individual interviews to identify and synthesize the timeline of procurement. Thereafter, the researcher utilized a categorizing strategy (Maxwell \& Miller, 2008) to identify the challenges of 
partnering between public and private actors and the ways of promoting partnering. This categorization was then utilized to identify how the findings relate to other findings by interpreting them within their context (Maxwell \& Miller, 2008), thus establishing an understanding of the relationship dynamics influencing the transition process from transactional arm's length tendering to partnering. The findings were reasserted and the differences resolved by the information gathered from the newspaper articles, which kept track of problems with the initial private home nursing provider. Furthermore, the information on tendering reports and from the interviews with the town's higher management gave insights regarding network-related factors that either hindered or promoted the transition towards partnership thinking.

The analysis shows the non-smooth transition process towards partnership thinking. In particular, it illustrates the relationship dynamics influencing the transition to partnering in centralized public procurement by identifying (1) the challenges related to utilizing collaborative procurement practices during contracting, (2) the challenges hindering partnering with the initial private home nursing provider during the procurement implementation and how the actors tried to mend their problematic relationship and (3) how partnering with the new private partner was promoted after that.

\section{Empirical case study}

\subsection{Challenges of partnering during contracting}

In town X, political influence on public procurements is strong. Public procurement units are answerable to designated committees that administer particular procurements and the way through which these procurements are implemented. The public procurement unit, responsible for purchasing public services for senior citizens, required therefore political will to support their plans when they started preparing the outsourcing of two of their home nursing districts in the beginning of 2011. Multiple political organs influenced the home nursing procurement by giving permission and guidelines for its implementation.

Town council decided on this and it is a political organ. Then through the town board, the thoughts of public procurement units are brought forward to these committees, which are both political organs. - The managers of procurement units must bring their plans to their committees and the committee agrees those explicit procedures. 
The politics influence procurements through the town's procurement strategy. The procurement strategy encourages the public procurement units to utilize new procurement practices that rely on stronger dialog and partnering between public and private organizations. Regardless of this, the development of the town's procurement culture towards partnership thinking is in its infancy and the procurement units "prefer doing procurements by means of the traditional model, although dialog with entrepreneurs would bring something new to these procurements" (Development Manager, Town X). This reflects the paradox between the formal procurement strategy, stemming from the higher management, and real procurement practices. The organizing method and autonomy of procurement units further segregates the units by preventing them from sharing of important experiences and procurement expertise.

There is no dialog between the public procurement units. Those procurement units are rather independent. - Perhaps we should create sort of shared templates for procurements, so that it would not always be necessary to start contracting from the scratch.

(Development Manager, Town X)

The procurement culture and organization promoted the inexperience of the public procurement unit to utilize collaborative procurement practices. Regardless of this, the procurement unit, making the home nursing procurement, tried to implement partnership thinking into their contracting by taking part in the innovative procurement project during 2011. In this project, the procurement unit was taught to apply collaborative procurement methods by establishing the dialog between them and potential private home nursing providers. Furthermore, the procurement unit relied on result-centered purchasing, instead of determining thoroughly the input required to implement procurement.

The former procurement model - determined thoroughly the input; the number of staff, what kind of staff was required and what kind of tasks this staff should do. In this procurement, we wanted to make this shift from this type of purchasing to purchasing results. - They taught us the model for technical dialog, wherein we discuss with potential private partners prior to releasing the tendering reports.

(Manager of Public Procurement Unit, Public Procurement Unit)

Therefore, the public procurement unit organized a technical dialog in spring 2012. This dialog with private home nursing providers was important as the procurement unit felt that their experience and the service providers' experience relating to the partial outsourcing and a 
new incentive system that relied on the performance promises of the private organizations were insufficient.

Home nursing is strange for us and them... There is not that much of experience from partial outsourcing of home nursing and that is the reason why we did not have any good examples from RFQs and at the same time from partial outsourcing.

(Manager of Public Procurement Unit, Public Procurement Unit)

Private home nursing providers were particularly inexperienced to give the promises that were utilized when their bids were assessed. Therefore, contracting "required lot of knuckling down from them - procurement expertise" (Manager of Public Procurement Unit, Public Procurement Unit). The purpose of technical dialog was thus twofold; to exploit the expertise of potential private organizations in forming an effective and rigorous RFQ and developing the incentive system by permitting private service providers to "refine the tendering reports" (Manager of Public Procurement Unit, Public Procurement Unit) and to "increase service providers' readiness to receive a new kind of RFQ -- so that it is not misunderstood" (Development Manager, Procurement Expert II).

The technical dialog with private service providers was nevertheless ineffective. The dialog was not helpful for preparing proper tendering reports and initiating a healthy partnership. The state of home nursing markets hindered particularly sharing and identifying issues with regard to forming the RFQ. Traditionally home nursing services are delivered by public organizations instead of private markets. Therefore, home nursing is new for public procurement, which underlay the lack of knowledge and experience in pricing home nursing services.

Home nursing markets are just developing. I think this is why municipalities do not understand their cost structures. Home nursing is somehow strange for them, what the product that they need to price is.

(CEO, New Private Home Nursing Provider)

Afterwards, I thought that is was rather unrealistic of service providers and for us that we thought that the private firm would be capable of delivering home nursing with ten persons less than the public home nursing.

(Manager of Public Home Nursing, Public Home Nursing Unit)

Thus, the public procurement unit released imperfect tendering reports that permitted private firms to play during the bidding by giving improper prices. This illustrates the competitive atmosphere surrounding procurements and reflects the transactional procurement logic of 
private service providers by showing the negative ways that private firms tend to use to try to win public biddings.

Potential private home nursing provider from town $\mathrm{Y}$ gave ridiculous prices and ridiculous promises. They played foul, which compelled us to interrupt the bidding and organize new discussions.

(Manager of Public Procurement Unit, Public Procurement Unit)

We need to look at these tendering reports from the service provider's perspective. Suppliers do not want these opportunities to mess with the system to remain in RFQs but we need to remember that they are forced to try to game the system as they are terrified that somebody else is doing that.

(Development Manager, Procurement Expert II)

In home nursing procurement, the playing interrupted the bidding process and obligated the public procurement unit to reorganize discussions with private service providers to reform their tendering reports. Regardless of rectifying their tendering reports, the procurement unit was again influenced by the competitive atmosphere surrounding procurements when they rendered their procurement decision. The threat of legal acts encouraged the procurement unit to apply the traditional procurement logic instead of partnership thinking by reinforcing their motivation to emphasize the price and select the private partner with an under-priced bid, although they had strong hesitations.

I think we should have more boldly rejected this bid as under-priced. - We consulted the lawyers that is it possible to reject this bid and they said that to not reject it or we will end up in the Market Court.

(Manager of Public Procurement Unit, Public Procurement Unit)

They should have had understood to reject the bid. In fact, the bid from us was also underpriced. Both were dumping or predatory pricing or whatever, but how do you prove that...

(CEO, New Private Home Nursing Provider)

Fig. 1 shows how partnering is hindered by the inexperience of the public procurement unit and potential private home nursing providers from the partial outsourcing of home nursing services and new procurement practices. This inexperience engendered problems to exploit the potential of collaborative procurement methods and to select the 'right' private partner. In particular, although the politics and the procurement strategy supported partnering by guiding and promoting new ways of purchasing, the actors had problems to transfer from transactional procurement logic to partnering. These problems emerged primarily from the 
procurement culture and organization in town $\mathrm{X}$, the competitive atmosphere surrounding procurement and the emerging home nursing markets.

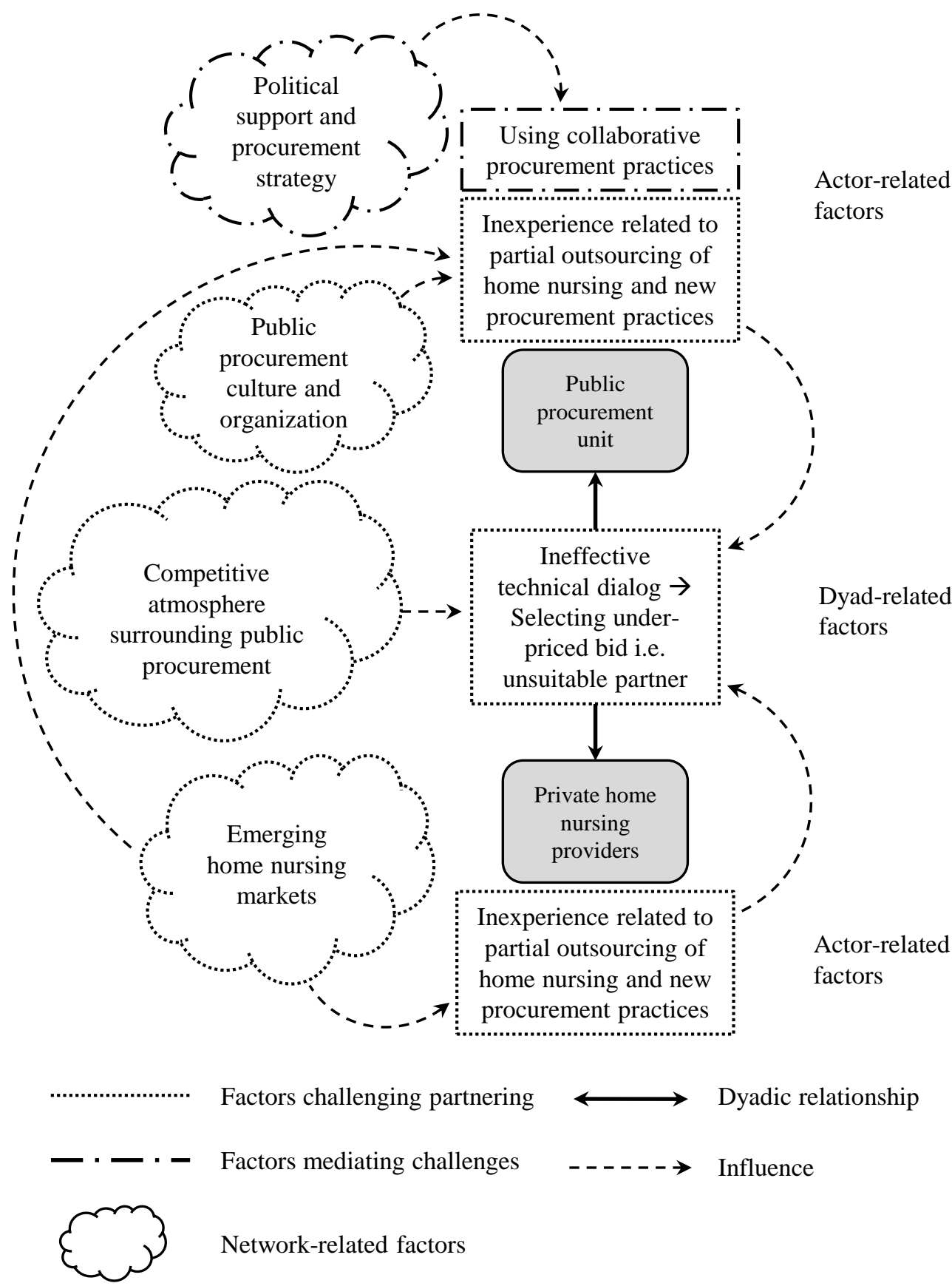

Fig. 1. Partnering between the public procurement unit and potential private home nursing providers during contracting. 


\subsection{Challenges of partnering and mending the problematic partnership during procurement implementation}

By requesting guarantees for their performance, the public procurement unit sought to challenge private home nursing providers to take further responsibility for delivering home nursing services. Instead of merely delivering services with the lowest possible costs, the goal of the new incentive system was to make sure that the private partner takes responsibility from the quality of those services and how they influence their users.

Public procurement units want the cheapest price and satisfaction, they want - that services influence positively their target groups. - Then they go to the bidding, they do the bidding by emphasizing the price and they think that those other goals are reached too, and sometimes they are, but it is not then within the hands of procurement unit. Instead, it is up to the service provider - and if they are awarded by the price, they perform like that. - Thus, what you promise during the bidding, you must take responsibility from that.

(Development Manager, Procurement Expert II)

This shows the interest of the public procurement unit in "reinforcing collaboration that is characterized by shared interests and goals between them and the private home nursing provider" (Manager of Public Procurement Unit, Public Procurement Unit), which shifted their procurement logic towards partnership thinking. The purpose of the procurement unit was to share their responsibility for the rehabilitation of senior citizens with the private partner by requesting commitments regarding customer satisfaction and on how the senior citizens' functional ability is retained. The procurement unit emphasized these commitments during the procurement implementation stage by rewarding for abiding by them and giving penalties for poor performance.

The goal was to - reward for good results and make them reimburse for bad results, poor productivity.

(Manager of Public Procurement Unit, Public Procurement Unit)

The incentive system facilitated the management of procurement by giving tools for the public units to monitor whether the private partner had fulfilled its promises and performed high-quality services. The system thus promoted partnering by urging tighter collaboration between the public units and the private home nursing provider and by requiring actors to create monitoring and knowledge sharing routines. This was acknowledged as being different from traditional transactional procurement practices. 
To perform this professionally and with high goals, it is not possible to purchase and then close your eyes and start doing something else. You really need to monitor and manage this process. - The new incentive system, the interaction and knowledge sharing it requires, is thus different from traditional procurement practices.

(Manager of Public Procurement Unit, Public Procurement Unit)

The initial private home nursing provider gave commitments regarding their performance. Nevertheless, they gave them with the lowest possible price to win the bid and thus without thinking through whether they could live up to them during procurement implementation. The excerpts illustrate that soon after the initial private home nursing provider began to deliver their home nursing services at the beginning of 2013 significant problems started to emerge. In particular, the private home nursing provider ran up against problems in bringing the procurement agreement into effect and fulfilling their promises at the given price.

They had problems to adhere to the procurement agreement.

(Service Manager II, Public Home Nursing Unit)

The home nursing provider $\mathrm{X}$ that gave an under-priced bid won the bidding - and when they realized that, they tried to do their home nursing poorly - They stepped onto a mine by giving this under-priced bid and carried on by stepping into the same mine by doing it poorly.

(Manager of Public Procurement Unit, Public Procurement Unit)

That is, the private home nursing provider delivered poor service quality, which led to reclamations from the senior citizens and their relatives. These reclamations referred to the different kinds of neglect and deficiencies, for example, inadequate visits to the homes of the senior citizens.

I remember that lots of reclamations emerged - Lots of deficiencies and neglect arose.

(Service Manager II, Public Home Nursing Unit)

Feedback embraced undone tasks and inadequate home visits, the hastiness of nurses, the unreachability of the private home nursing provider, knowledge sharing problems and that the private home nursing provider did not nominate particular nurses to their patients.

(Newspaper, March 2013)

The problems of the private home nursing provider reflected their pressure to diminish costs, which created recruitment and HRM problems. The private partner had difficulties in hiring good nurses and keeping them, as they tried to perform home nursing with too few nurses. 
The recruitment of new staff was a stumbling block. - The recruitment and how it was managed was perhaps the main reason for the initial private home nursing provider to fail. The interchange of staff was massive and they had unqualified substitutes.

(Manager of Home Nursing Unit, Public Home Nursing Unit)

At the beginning, we increased the number of nurses. That was the first thing what we did. They did not have enough nurses as they were doing morning visits still in the evening time.

(Team Leader, New Private Home Nursing Provider)

The staff members of the town's home nursing further hampered the efforts of the private home nursing provider to perform high-quality services by resisting sharing their tacit knowledge. This type of knowledge exchange is important, as home nursing staff must know the patients and their individual habits. The strong resistance towards the partial outsourcing and collaboration existed particularly at the beginning of procurement implementation, as it required strong adjustments to public home nursing.

In the beginning, the faltering did not just result from the failings of the private home nursing provider. There was the town's own home nursing staff, their sort of inability to collaborate. I think the employees of public home nursing were displeased and they were not happy to transfer these two home nursing districts to them.

(Manager of Public Procurement Unit, Public Procurement Unit)

The tensions between the three actors became aggravated by external parties when politics started to receive feedback from the public. The poor quality of the home nursing brought about critical articles in the local newspapers during spring 2013, which created pressure for the public procurement unit to remedy the existing problems. To resolve the unexpected tensions between the public home nursing unit and the private home nursing provider, the procurement unit started to immediately negotiate with the private partner during spring 2013 to get to the bottom of what was not working and how to restore their problematic partnership. Nevertheless, these negotiations with the private partner were ineffective. That is, although harmful, the reclamations themselves did not bring about the end of the partnership between the public units and the private service provider; rather it was the inability and weak attitude of the private partner to rectify their problems. Instead of resolving the reclamations and other problems, the private home nursing provider repudiated that the problems existed and they invariably broke their commitments to rectify them. Furthermore, the private home nursing provider argued against penalties that they were given for breaking these commitments. This reflected the transactional procurement logic of private 
partner by showing their inability to collaborate and a lack of commitment to the procurement goals.

Nothing that they promised was kept to. The employees were extremely distressed with this non-stop customer feedback. The monthly meetings with them were chaotic and they admitted to nothing. They did not see anything wrong in their performance and they tried to contest the penalties all the time.

(Manager of Home Nursing Unit, Public Home Nursing Unit)

The town has asked reports from these reclamations and how they are to be fixed. The town has received reports on reclamations but the private home nursing provider has not realized that these required improvements that would influence the quality of home nursing.

(Newspaper, June 2013)

The tensions influenced the cohesiveness of the three actors and their working atmosphere by impairing trust, which at last required the public procurement unit to issue a threat of the notice of rescission, just six months after starting the procurement implementation.

If you think that you always need to doubt and check things, it is pretty rough. - I got the feeling - that there is nothing that works within this collaboration.

(Manager of Home Nursing Unit, Public Home Nursing Unit)

After six months we had to give notice of rescission for the initial private home nursing provider to put things right. - There was just too many reclamations. - It was overwhelming and so clearly true that we could not listen anymore.

(Manager of Public Procurement Unit, Public Procurement Unit)

From the public units' perspective this was exceptional and undesirable. Thus, they had a strong urge to make things work to show the public that the outsourcing was the right decision and to avoid further adjustments in public home nursing. Regretfully, regardless of these efforts to repair the situation, the initial private home nursing provider was unable to offer a feasible plan to resolve their problems, and thereby, preserve their reputation; they forfeited their procurement agreement to a new private service organization in the end of 2013.

In august, we had to state that the initial private home nursing provider was not capable of resolving their problems and that is when they asked whether they could make a deal from this agreement with another private service provider.

(Manager of Public Procurement Unit, Public Procurement Unit) 
The initial private home nursing provider had problems in delivering home nursing in town $\mathrm{X}$ - so it is not a secret that they paid us to take this procurement agreement. They wanted to get rid of it while saving face.

Fig. 2 illustrates how partnering between the public units and the initial private home nursing provider during the procurement implementation stage was hindered by performance failures, emerging from the internal resistance in public home nursing and the pressure of private partner to deliver home nursing services at minimum cost. These problems led to the restoring efforts of the problematic partnership relationship, which were thought to be hindered by the private partners' transactional procurement logic. That is, the private partner seemed unable to collaborate by having poor conflict resolution skills and the lack of commitment to the procurement goals, which established a lack of trust between the three actors. Although the adjustments in public home nursing and the pressure from the network level increased the motivation of the public procurement unit to repair the partnership, the procurement unit and the initial private home nursing provider were incapable of finding ways of proceeding with their collaboration and thus the PPP was terminated. 


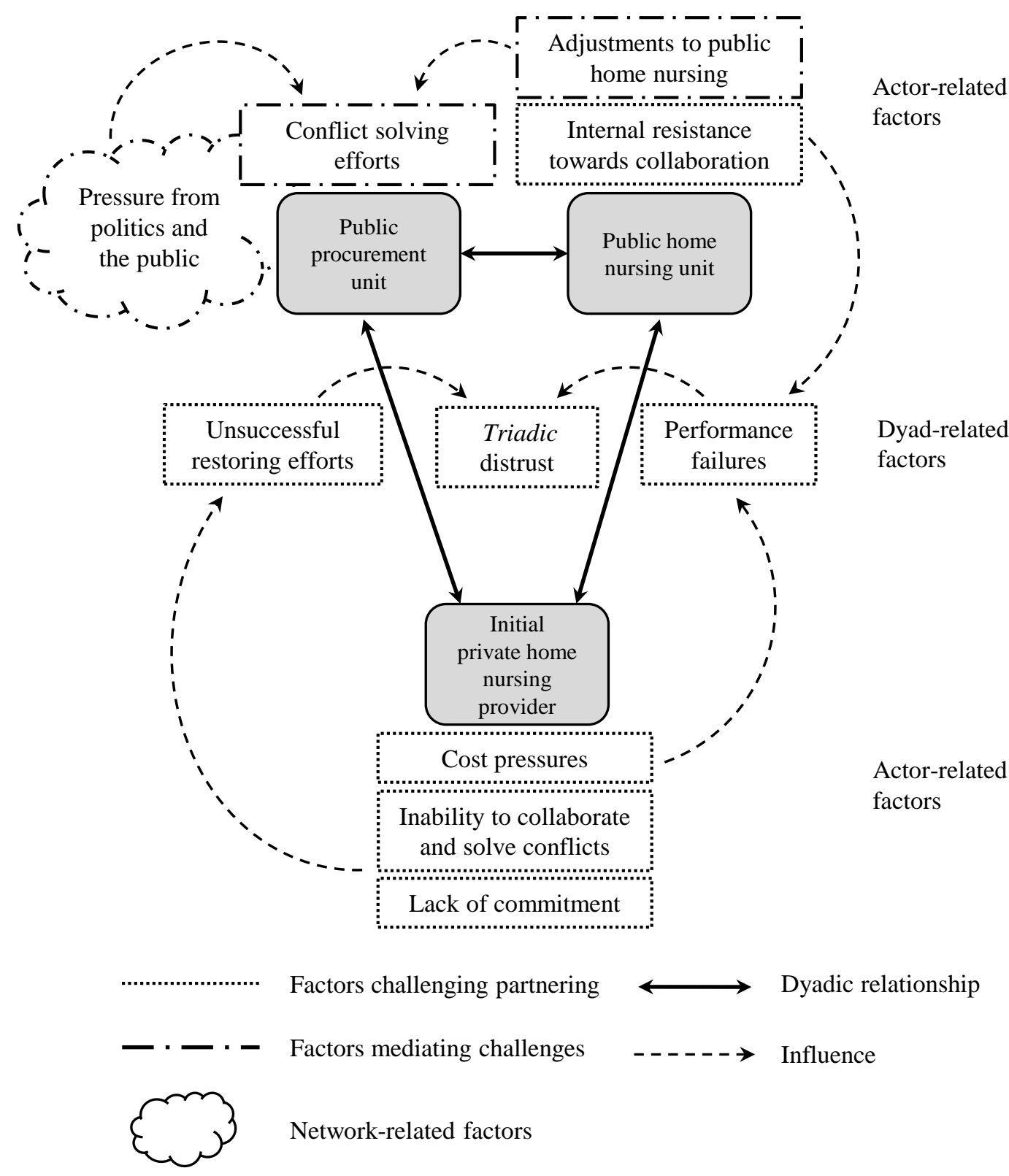

Fig. 2. Partnering with the initial private home nursing provider during procurement implementation.

\subsection{Towards partnership thinking with the new private home nursing provider}

The new private home nursing provider started the delivery of their home nursing services at the end of 2013 by purchasing the procurement agreement from the initial private service provider. The new private home nursing provider recognized that the transaction was unprofitable and established pressure to improve the cost-effectiveness of their service delivery. Nevertheless, its interpersonal relationships with the public procurement unit and prior failures in emerging home nursing markets tempted the organization to help their longterm public partner and learn more about home nursing service delivery and its markets. 
We tried for years to make it profitable - and then we decided that we are going to quit this business. - But then came this town $\mathrm{X}$ - They are an important customer for us and we appreciate the work that this particular procurement unit has done... - I thought that this is a good test field for us to see whether we have learned anything from the past, whether home nursing markets have developed somehow and - whether we can do this.

(CEO, New Private Home Nursing Provider)

The politicians and inhabitants of town $\mathrm{X}$ influenced the procurement implementation with the new private partner by pressuring the public procurement unit and the public home nursing unit to remedy the problems related to the home nursing. The inhabitants had particularly strong reservations about whether anything was going to change, just by changing the initial private service provider with the new private organization.

At the beginning, I was the spokesperson for this new private service provider so that - those images and disappointments that were experienced with the initial service provider would go away.

(Service Manager II, Public Home Nursing Unit)

Therefore, the public units had a strong motivation to learn from the mistakes with the initial private partner and to make things work by doing things differently. This manifested itself through new working practices. The new private home nursing provider agreed to this as they understood how relevant it was for the public units to succeed.

They took our message seriously when we said that it is not possible to fail this time at the customer level. - Therefore, those pretty heavy collaborative structures were created and it has been really useful that they emerged at that point of time. - If we would have failed, we would have received lots of feedback from multiple directions.

(Manager of Public Procurement Unit, Public Procurement Unit)

The pressure to learn from past failures and mistakes established reciprocal knowledge exchange routines and processes at the strategic and the procurement implementation levels, which reinforced the partnership thinking between the public units and the new private home nursing provider. In their meetings, the public procurement unit and the new private home nursing provider established a shared understanding on the procurement goals and recognized that at strategic level they share an interest in improving home nursing services and the emerging home nursing markets. Thus, the new private home nursing provider shared information on their service delivery to assist the public units in benchmarking their performance in public home nursing. In return, knowledge sharing with the procurement unit facilitated the new private home nursing provider's interest to improve their home nursing 
and influence home nursing markets; that is, how home nursing services are priced within these markets. The shared understanding from jointly agreed procurement goals and resulting two-way knowledge exchange showed the efforts of the procurement unit and the new private home nursing provider to reach mutual satisfaction and joint learning. This illustrates the change in their procurement logic to partnering.

Together we have tried to improve home nursing as a business. They have an interest towards it and we have an interest towards it. - We have shared information, for example, about the processes of public home nursing, financial figures. They have done that as well; they discuss openly about these things. - We have discussed with their management about those home nursing provisions, how we could develop home nursing and its procurement, pricing and perhaps that service note system. - We have tried to create a win-win situation that with the same information, they can improve their business and we can improve public home nursing. (Manager of Public Procurement Unit, Public Procurement Unit)

We talk about the future of home nursing. They tell what they expect from us and I tell them honestly what our goals are. - We discuss about general, national things... We spar. They hear things at national level through their channels. I hear things through my channels and this is how we share information. It starts from there that if we discuss, we both learn something.

(CEO, New Private Home Nursing Provider)

The shared understanding between the public procurement unit and the new private home nursing provider from procurement goals facilitated the implementation of high-quality home nursing. It improved actors' feeling of cohesiveness and capability to work together by reinforcing their trust and empowering the actors to understand the expectations of their partner and how their individual actions contribute to jointly agreed procurement goals.

If you have shared understanding about key things, you trust that you pay attention to those things and then again the private home nursing provider pays attention to them.

(Manager of Home Nursing Unit, Public Home Nursing Unit)

I know what they are expecting from us... We understand their strategy and they are pretty open about what our role is in that.

(CEO, New Private Home Nursing Provider)

The problems with the initial private home nursing provider gave though rise to tighter monitoring and intensive knowledge sharing routines between the public home nursing unit and the new private service provider. Thus, the actors exchanged information daily to share their responsibility for the rehabilitation of senior citizens and to initiate home nursing services for them. Furthermore, the public home nursing unit and the new private service 
provider participated in monthly meetings to revise these services and to settle reclamations and other types of problems together.

We have agreed with the public home nursing that during the mornings we have this phone line so that they can reach us and we can reach them. - They need to initiate those services so that we can access customer information. - These types of discussions are day-to-day discussions.

(Team Leader, New Private Home Nursing Provider)

We created this monthly system for these monthly meetings - where we talk about problems - and proactively resolve them together. I coordinate this collaboration - and it has a specific rhythm. We have specific dates - when we meet - so that certain billing processes go ahead on time. In that sense, it is intense, and I think it is routine-like, or better, it has a rhythm.

(Manager of Home Nursing Unit, Public Home Nursing Unit)

The procurement implementation rested on the thorough supervising of the private partner on their service delivery. For this purpose, the new private home nursing provider nominated a nurse to make sure that their services were being implemented effectively, but resiliently, and that their day-to-day communication with the public home nursing unit flowed. Furthermore, the private partner sought to resolve problems proactively and professionally through discussions, which showed their flexibility and commitment to make things work with their public partners.

Things that they are not even familiar with are brought forward. - No matter what those things are, we respond to them properly and we always try to improve our performance.

(Regional Manager, New Private Home Nursing Provider)

This addresses the way in which the public home nursing unit and the new private home nursing provider collaborated to perform home nursing services, which established a trustful and sincere partnership-like atmosphere between them.

It feels that with this private home nursing provider it is possible to develop mutual trust. Through their monitoring, they bring forward these unpleasant things and they do not try to hide them. Those things are talked about freely. - It influences things, as then it is not necessary to question what they say.

(Manager of Home Nursing Unit, Public Home Nursing Unit) 
Discussions between us are sincere and I do not feel that if something happens that I cannot say anything or that I cannot tell that something has happened. - They have given us constructive criticism, but I have never felt that they think that we cannot do this. - I think we both feel that - the reason why we are doing this is for the end user who we are taking care of.

(Regional Manager, New Private Home Nursing Provider)

Fig. 3 shows how the transitioning towards partnership thinking is promoted by shared understanding about jointly agreed procurement goals and commitment to them, emerging from the urge to learn from past mistakes and failures. In particular, the partnering relied on knowledge exchange that reinforced collaboration, with reciprocity and joint learning, which engendered a trustful and sincere working atmosphere in the triad and thus promoted partnering. 


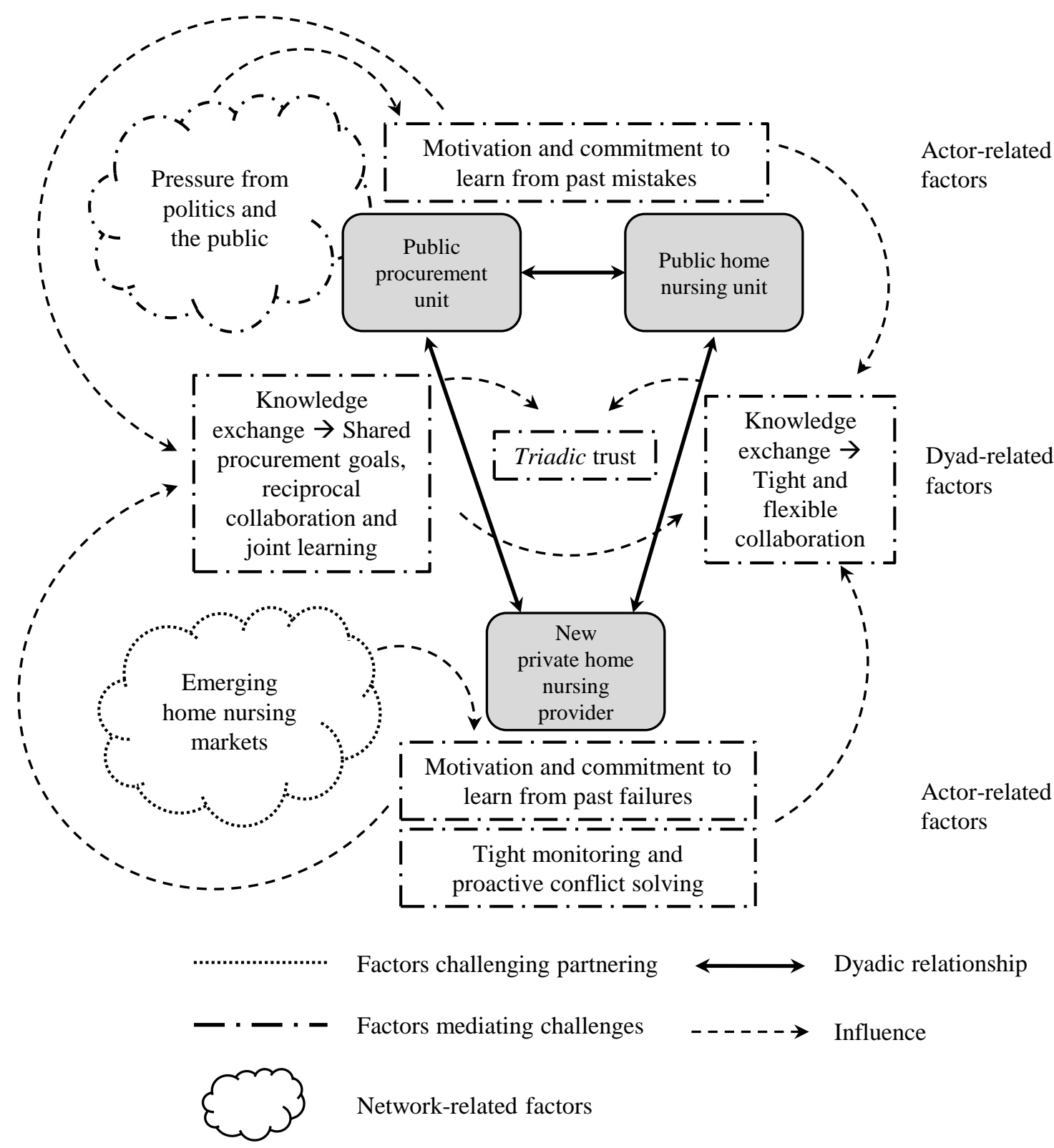

Fig. 3. Partnering with the new private home nursing provider during procurement implementation.

\section{Discussion}

In this part, the challenges of partnering and how to promote it are discussed to illustrate the relationship dynamics between public and private actors during the transition to partnering in the triadic setting. To address the research question of how is the transition process of public and private actors towards partnership thinking influenced by the relationship dynamics in the triadic setting, Fig. 4 reiterates Figs. 1-3 and demonstrates the procurement logic underlying the dyadic relationship to influence the triadic partnering within and between different procurement stages. Furthermore, the transactional procurement logic of single actor 
and the logic underlying the relationship of two actors is shown to engender and intensify the problems of triad and partnering between the two actors is suggested to promote reciprocal collaboration in the triad.

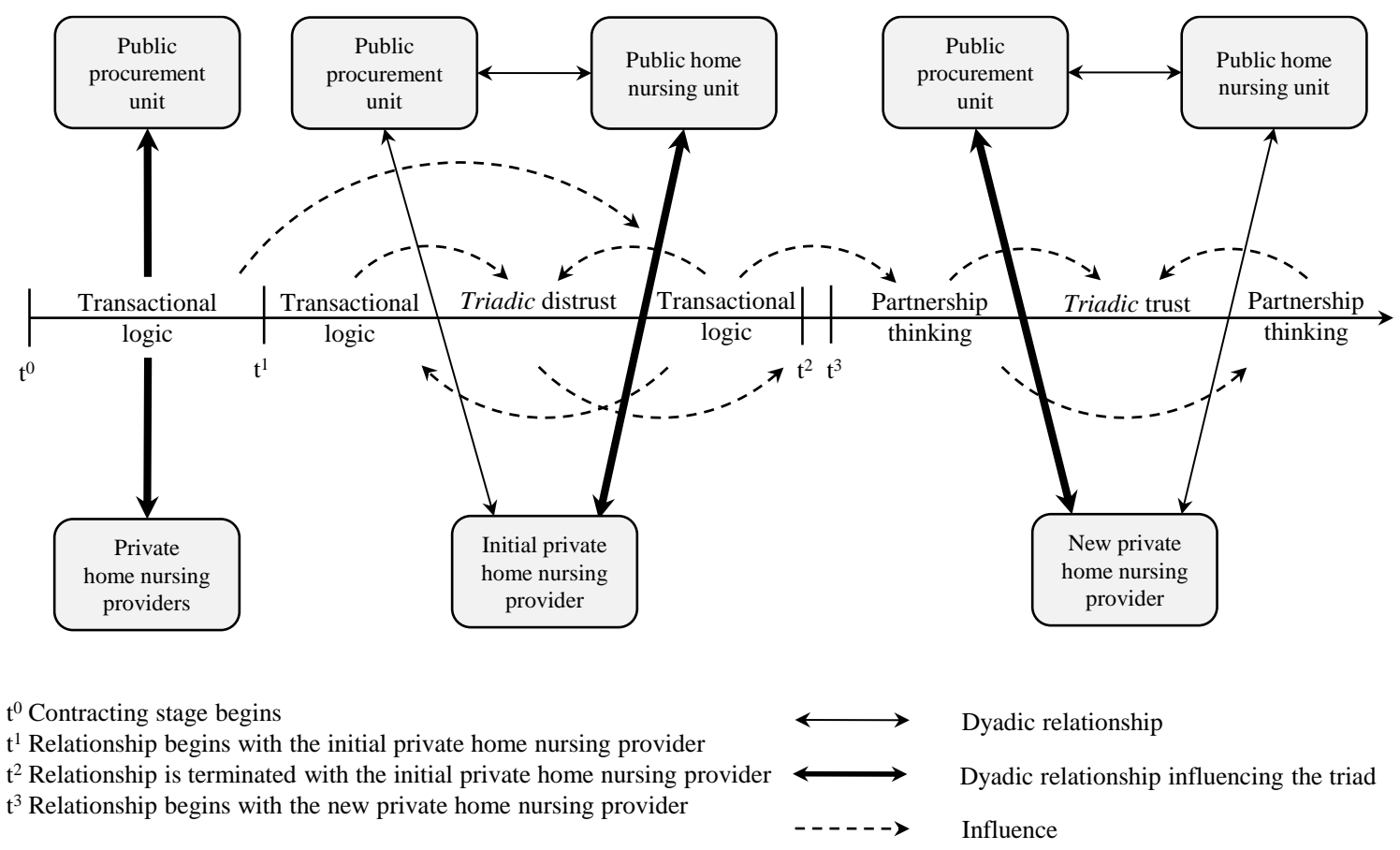

Fig. 4. Dynamics of the transition process of public and private actors towards partnership thinking in the triadic setting.

In this research paper, the transactional procurement logic is presented to hinder the partnering between the professional public purchaser and potential private organizations during contracting and bring about problems at the procurement implementation stage between the public unit managing the procurement implementation and the private partner. The challenges of partnering were thus highly interlinked and they emerged primarily from the transactional arm's length procurement logic of single actor or the logic that underlie the relationship of two actors. To identify further these challenges and to answer the sub question of what are the challenges that hinder the transitioning towards partnership thinking in public procurement, the transactional procurement logic is suggested to engender problems by retaining the traditional transactional arm's length procurement culture and organization. This supports the notion of Erridge and Greer (2000) presenting that public procurement culture tends to hinder the development of interorganizational relationships and trust. In home nursing procurement, the tradition of making procurements arm's length established inexperience of public and private actors in partnering. In contracting, the transactional 
procurement logic hindered the transitioning towards partnership thinking by impeding the utilization of collaborative procurement practices, creating a competitive atmosphere in the procurement and thus tempting the professional public purchaser to initiate a partnership with the lowest and therefore at times an unsuitable bidder.

Furthermore, the transactional procurement logic in contracting stage is shown to galvanize the actors to rely on similar kinds of thinking during procurement implementation. In home nursing procurement, contracting problems established insufficient performance, while the transactional procurement logic hampered partnering by promoting the negative attitude of the private partner in resolving conflicts and demonstrating their inability to collaborate and commit themselves to the procurement goals. Interestingly, and rather similarly to the term "triadic trust" (see Svensson, 2004), the problems created tensions first in the dyadic relationship of the public unit managing procurement implementation and the private organization and then within the triad by establishing leveraging the distrust. The transactional procurement logic taken by the single actor of triad thus created triadic distrust and harmed the actors' feeling of cohesiveness and capabilities to work together towards the shared procurement goals. This shows the need for each of the three actors to apply partnership thinking during the procurement process as failure to implement this change is illustrated to result in failure to develop the triad. The transactional procurement logic is thus suggested to establish ties that Gross (1956: 175) determines as "consensual ties", which are described merely to rest on some kind of agreement, and therefore disharmony and conflicting views are likely to influence actors' working atmosphere negatively and break up the triad. In this type of triad, the internal ties and cohesiveness between the actors are weak and thus the triad resembles the form of sets of connected actors (see Vedel et al., 2016).

In home nursing procurement, the problems with the initial service provider motivated a change in the procurement logic with the new private partner. In particular, to address the sub question of how is partnering promoted during the transitioning towards partnership thinking in the triad, establishing a shared understanding from jointly agreed procurement goals (Jamali, 2004; Lawther \& Martin, 2005) is identified to reinforce the change from transactional arm's length tendering to partnering by permitting actors to show their commitment (Jacobson \& Choi, 2008; Zou et al., 2014) and create effective mechanisms for reciprocal collaboration and knowledge exchange, resolving problems and developing mutual triadic trust. The shared understanding from jointly agreed procurement goals prevailed initially between the dyadic relationship of the professional public purchaser and the private organization, from which it strengthened the ties between the other two actors and 
empowered them to work together to reach those goals. This increases the importance of "bridging" (see Li \& Choi, 2009) throughout the triad, wherein the trustworthy and collaborative relationship of two are utilized to foster reciprocal knowledge exchange and trust between the other two actors of the triad. In the light of the research of Gross (1956), the transitioning towards partnering thus requires both "consensual ties", emerging from the procurement agreement, and "symbiotic ties", which are argued to stem from actors' interdependence and to aid them in forming a stronger group-like-triad where internal ties between the actors are strong and their triad is more cohesive (see Vedel et al., 2016).

The embeddedness of relationships in their network structures (Anderson et al., 1994) is further identified to establish dynamics that influence the transition to partnering between public and private organizations. The emerging nature of private markets brought particularly challenges for initiating and nurturing PPPs by hampering in determining shared procurement goals and in preparing rigorous tendering reports. In home nursing procurement, the professional public purchaser and potential private service providers were short of procurement examples, which yielded problems in estimating service costs and compiling tendering reports. Nevertheless, the challenges that emerge from the market characteristics are identified important not just as they work to hinder partnering, but with their way of gluing actors together, where potential threats are recognized and viewed as opportunities. In home nursing procurement, the collaboration with the new private organization was influenced by the state of home nursing markets. The three actors shared an interest in improving the emerging home nursing markets, which shows how they needed each other to shape the private market structures.

Finally, political support during contracting is find to motivate public organizations to purchase differently. This highlights the role of politics in setting the procurement strategy and in empowering otherwise inexperienced public organizations to try new and interactive procurement practices. Furthermore, the politicians and the inhabitants of municipalities may act as network-related actors to strengthen the ties within the triad. In home nursing procurement, they were identified as promoting the relationship-restoring efforts of the professional public purchaser. 


\section{Conclusions}

\subsection{Theoretical contribution}

This research paper examined the transition process of public and private actors who are moving from arm's length tendering to partnering in the context of centralized public procurement. The research draws on the literature of partnership relationships between public and private organizations and their underlying mechanisms, which is integrated it with the research on relationship dynamics in triads to add to the knowledge of the dynamic transitioning of public and private actors towards partnership thinking in three particular ways.

First, by stressing the embeddedness of PPP relationships within their network structure, the research increases the knowledge of the transition process towards partnership thinking in public procurement as a whole. The transitioning towards partnership thinking in public procurement is investigated by the multiplicity of challenges and how to promote it at different levels, in the context of centralized public procurement, to better understand the intricacy of the transition process and how different procurement logics influence partnering. The understanding from the transition to partnering is argued to advantage in managing PPP relationships by illuminating why public and private actors run up against problems in PPPs and how these partnerships are strengthened. The research advises that the traditional transactional procurement logic hinders the transition process by establishing challenges for initiating and nurturing PPPs, but the actors may attempt to manage them by establishing a shared understanding about jointly agreed procurement goals and building trust. This is further promoted or hindered by the external network of PPP relationship throughout the procurement process. In the literature, the promoters (e.g., Jamali, 2004; Li et al., 2005; Zou et al., 2014) and barriers of PPPs (e.g., Erridge \& Greer, 2000; Klijn \& Teisman, 2003) are widely recognized. Nevertheless, this research stream has centered less attention to the transition process towards partnership thinking than this paper has. The research identifies the challenges related to the transition process and furthers the understanding of how these challenges influence partnering, how underlying transactional procurement logic creates the challenges in partnering and of how partnership thinking requires changing this procurement logic.

Second, the transitioning literature is extended by exploring the relationship dynamics of the transition process of public and private actors towards partnership thinking in the 
triadic setting. The research suggests that the partnering between public and private organizations is dynamic and thus stresses relationship dynamics as being an important part of the transitioning towards partnership thinking. The procurement logic of single actor and the logic underlying the relationship of two actors influence triadic partnering during the centralized public procurement process; that is, the transactional procurement logic of single actor and dyadic relationship engender and intensify the problems of triad and a shared understanding about jointly agreed procurement goals between two actors promote partnering in the triad. This illustrates the connectedness of relationships between three actors (Vedel et al., 2016) and increases the knowledge of how to leverage the partnership thinking throughout the triadic partnership relationship and thus the public procurement process. Managing the transition process of public and private actors towards partnering requires an understanding of the challenges of individual dyadic relationships and how they may influence the triadic partnering within and between different procurement stages and thereafter promoting the partnering by relying on relational mechanisms, particularly by establishing a shared understanding from jointly agreed procurement goals and developing trust. This supports the finding of relational mechanisms being important for transitioning towards partnership thinking in public procurement (Hartmann et al., 2014) together with formal procurement agreements. The research extends the understanding from the interplay between new forms of contractual and relational governance (Zheng et al., 2008) by investigating the dynamics between different procurement logics creating them.

Third, the research fosters the understanding related to relationship dynamics in the triad, particularly by identifying how the activities of single actor might strengthen or harm triadic partnering by influencing the development of trust. Hartmann et al. (2014) state the strategic procurement practices of professional public purchaser to reinforce partnering. This research lends support to this finding, but identifies that each of the three parties engaged in the triad must understand and address particular ways of how to manage and reinforce their partnership. This is relevant in service outsourcing context where actors tend to confront challenges to manage service delivery (van Iwaarden \& Van der Valk, 2013). Regardless of this, research examples related to service triads (e.g., van Iwaarden \& Van der Valk, 2013), particularly in a public setting, are still scarce. Therefore, the empirical analysis carried out within a public service outsourcing setting constitutes a further contribution by this research. 


\subsection{Managerial implications}

The managerial implications of this research are twofold. The research gives insights into the challenges hindering the transition to partnering to embolden managers to scrutinize their partnership relationships and identify problems that may hinder them. Suggestions for what partnering requires from public and private actors are further proposed to assist managers to recognize how they should change their thinking and demeanor to transit towards partnering. In attempting to apply partnership thinking, managers should pursue to create knowledge sharing routines and practices to negotiate and agree on shared procurement goals during the contracting and thereafter to build mechanisms to collaborate and jointly monitor the quality of the procurement implementation. Mutual knowledge exchange is important for trust and commitment, which are viewed as strengthening the interorganizational ties and aiding in moderating the potential tensions between public and private organizations that may emerge from actors' inexperience to build and sustain partnerships. In public procurement setting, nevertheless, utilizing interactive and collaborative procurement practices requires a movement away from traditional arm's length procurement practices, which may need promoting by political bodies and higher public management. Therefore, this research has implications not just for the managers of organizations involved in PPP relationships, but is relevant to higher public management and public policy, in formulating procurement strategies and principles. In particular, flexibility is needed in national and international procurement laws and regulations to boost and authorize individual public organizations to find new and collaborative, but fair, ways of carrying out procurements.

The research increases the understanding of the relationship dynamics when moving from traditional transactional procurement logic towards partnership thinking; that is, how the procurement logic of single actor and the logic underlying the relationship of two actors influence the triad and how partnership thinking requires leveraging throughout the triadic partnerships and the public procurement process. From the managers' perspective, this implies that contracting practices require attention; professional public purchasers and private organizations must take note of how collaborative their contracting practices are and how they may influence partnering so that they can create strong basis for further partnering during procurement implementation. Therefore, weight is put on developing new kinds of interactive contracting expertise and know-how and increasing collaboration and negotiations between public and private actors to determine procurement goals, which makes "bridging" (Li \& Choi, 2009) possible between different procurement stages. Private firms might though 
influence this process negatively by creating a competitive atmosphere in the procurement and thus motivate professional public purchasers to rely on transactional procurement logic instead of partnership thinking. The standpoint taken towards private firms in public procurement is thus important; the transition towards partnership thinking is suggested to require engaging private actors in the contracting and negotiating the procurement goals with them. In procurement implementation, the partnering requires the three actors to find mutual ways of coordinating their collaboration, as it permits partners to increase reciprocal knowledge exchange and develop working conflict resolution mechanisms that facilitate the development of triadic trust and commitment.

\subsection{Limitations and future research}

The trustworthiness of this research is improved by the careful choice for the empirical research setting and its interviewees. Furthermore, using different kinds of data types enabled a triangulation of the data and by describing the research design, the researcher sought to increase the possibilities of the reader to understand and repeat the research. The research setting has its limitations. For sensitivity reasons, the empirical part captures the perspective of the initial private home nursing provider indirectly. By taking the responsibility for the procurement agreement, the new private partner agreed to perform the home nursing with the existing terms and staff, which permitted them to understand the internal problems that the initial private service provider had and suggest how they influenced the initial home nursingrelated PPP. The interpretations related to the termination of this PPP are further supported by newspaper articles that confirmed the chain of events and the stories given by the public organizations on what happened with the initial private partner.

This research focused on the non-smooth transition process towards partnership thinking during the centralized home nursing procurement. Future research should include different kinds of public procurement contexts to increase understanding of how procurement logics influence partnering efforts between public and private organizations and to identify thoroughly why some fail to partner while others manage to initiate and sustain strong PPP relationships. Furthermore, the empirical analysis gives hints on which characteristics of private markets influence PPPs. In the market-shaping literature, public organizations are recognized to shape private markets through their procurements (e.g., Edler \& Georghiou, 2007). The markets and how they shape PPPs remain though unexplored and thus future research on this matter is recommended. 


\section{Acknowledgements}

I thank the three reviewers for their insightful feedback that greatly improved this research paper. The research is part of the BRIIF research project funded by Smart Procurement Programme of Finnish Funding Agency for Innovation (TEKES) whose financial support is gratefully acknowledged. Gratitude is further expressed to the interviewees for their time and effort.

\section{References}

Anderson, J. C., Håkansson, H., \& Johanson, J. (1994). Dyadic business relationships within a business network context. Journal of Marketing 58(4), 1-15.

Anderson, J. C., \& Narus, J. A. (1990). A model of distributor firm and manufacturer firm working partnerships. Journal of Marketing 54(1), 42-58.

Arksey, H., \& Knight, P. T. (1999). Interviewing for Social Scientists: An Introductory Resource with Examples. London: Sage.

Arlbjørn, J. S., \& Freytag, P. V. (2012). Public procurement vs private purchasing: Is there any foundation for comparing and learning across the sectors? International Journal of Public Sector Management 25(3), 203-220.

Barlow, J., Roehrich, J., \& Wright, S. (2013). Europe sees mixed results from public-private partnerships for building and managing health care facilities and services. Health Affairs 32(1), 146-154.

Biernacki, P., \& Waldorf, D. (1981). Snowball sampling: Problems and techniques of chain referral sampling. Sociological Methods and Research 10(2), 141-163.

Bovaird, T. (2006). Developing new forms of partnership with the 'market' in the procurement of public services. Public Administration 84(1), 81-102.

Brown, T. L., \& Potoski, M. (2003). Contract-management capacity in municipal and county governments. Public Administration Review 63(2), 153-164.

Brown, T. L., Potoski, M., \& Van Slyke, D. M. (2007). Trust and contract completeness in the public sector. Local Government Studies 33(4), 607-623.

Campbell, N. C. (1985). An interaction approach to organizational buying behavior. Journal of Business Research 13(1), 35-48.

Caplow, T. (1956). A theory of coalitions in the triad. American Journal of Sociology XXI(August), 489-493.

Cowton, C. J. C. J. (1998). The use of secondary data in business ethics research. Journal of Business Ethics 17(4), 423-434.

Denzin, N. K. (1978). The research act: A theoretical introduction to Sociological methods. New York: McGraw Hill.

Dubois, A., \& Gadde, L.-E. (2014). Systematic combining - A decade later. Journal of Business Research 67(6), 1277-1284.

Easton, G. (1995). Methodology and industrial networks. In K. Möller, \& D. T. Wilson (Eds.), Business marketing: An interaction and network perspective (pp. 411-492). Boston: Kluwer Academics Publishers.

Edler, J., \& Georghiou, L. (2007). Public procurement and innovation - Resurrecting the demand side. Research Policy 36(7), 949-963. 
Eisenhardt, K. M. (1989). Building theories from case study research. Academy of Management Review 14(4), 532-550.

Erridge, A., \& Greer, J. (2000). Policy network analysis of UK central government civil procurement. Public Policy and Administration 15(4), 25-49.

Erridge, A., \& Greer, J. (2002). Partnerships and public procurement: Building social capital through supply relations. Public Administration 80(3), 503-522.

Erridge, A., \& McIlroy, J. (2002). Public procurement and supply management strategies. Public Policy and Administration 17(1), 52-71.

Essig, M., \& Batran, A. (2005). Public-private partnership - Development of long-term relationships in public procurement in Germany. Journal of Purchasing and Supply Management 11(5), 221231.

Gross, E. (1956). Symbiosis and consensus as integrative factors in small groups. American Sociological Review 21(2), 174-179.

Guest, G., Bunce, A., \& Johnson, L. (2006). How many interviews are enough? An experiment with data saturation and variability. Field Methods 18(1), 59-82.

Gutek, B. A., Groth, M., \& Cherry, B. (2002). Achieving service success through relationships and enhanced encounters. Academy of Management Executive 16(4), 132-144.

Guzmán, F., \& Sierra, S. (2012). Public-private collaborations: Branded public services? European Journal of Marketing 46(7/8), 994-1012.

Håkansson, H., \& Snehota, I. (1995). Developing relationships in business networks. London: Routledge.

Halinen, A., \& Mainela, T. (2013). Challenges of longitudinal field research in process studies on business networks. In M. E. Hassett, \& E. Paavilainen-Mäntymäki (Eds.), Handbook of longitudinal research methods in organisation and business studies (pp. 185-204). Cheltenham: Edward Elgar Publishing.

Halinen, A., \& Tähtinen, J. (2002). A process theory of relationship ending. International Journal of Service Industry Management 13(2), 163-180.

Halinen, A., \& Törnroos, J.- $\AA$. (2005). Using case methods in the study of contemporary business networks. Journal of Business Research 58(9), 1285-1297.

Hartmann, A., Roehrich, J., Frederiksen, L., \& Davies, A. (2014). Procuring complex performance: The transition process in public infrastructure. International Journal of Operations and Production Management 34(2), 174-194.

Havila, V., Johanson, J., \& Thilenius, P. (2004). International business-relationship triads. International Marketing Review 21(2), 172-186.

Hodge, G. A., \& Greve, C. (2007). Public-private partnerships: An international performance review. Public Administration Review 67(3), 545-558.

Holma, A., Björk, P., \& Virtanen, H. (2009). Co-operation facilitators in dynamic business triads. IPM Journal 1(3), 75-94.

Holmlund, M., \& Törnroos, J.-Å. (1997). What are relationships in business networks? Management Decision 35(4), 304-309.

Hood, C. (1991). A public management for all seasons? Public Administration 69(1), 3-19.

van Iwaarden, J., \& Van der Valk, W. (2013). Controlling outsourced service delivery: Managing service quality in business service triads. Total Quality Management and Business Excellence 24(9-10), 1046-1061.

Jacobson, C., \& Choi, S. O. (2008). Success factors: Public works and public-private partnerships. International Journal of Public Sector Management 21(6), 637-657.

Jamali, D. (2004). Success and failure mechanisms of public private partnerships (PPPs) in developing countries: Insights from the Lebanese context. International Journal of Public Sector Management 17(5), 414-430. 
Karjalainen, K. (2011). Estimating the cost effects of purchasing centralization - Empirical evidence from framework agreements in the public sector. Journal of Purchasing and Supply Management 17(2), 87-97.

Klijn, E. H., \& Teisman, G. R. (2003). Institutional and strategic barriers to public-private partnership: An analysis of Dutch cases. Public Money and Management 23(3), 137-146.

Kumaraswamy, M. M., Ling, F. Y., Anvuur, A., \& Rahman, M. M. (2007). Targeting relationally integrated teams for sustainable PPPs. Engineering, Construction and Architectural Management 14(6), 581-596.

Kwak, Y. H., Chih, Y., \& Ibbs, C. W. (2009). Towards a comprehensive understanding of public private partnerships for infrastructure development. California Management Review 51(2), 5178.

Langley, A. (1999). Strategies for theorizing from process data. Academy of Management Review 24(4), 691-710.

Lawther, W. C., \& Martin, L. L. (2005). Innovative practices in public procurement partnerships: The case of the United States. Journal of Purchasing and Supply Management 11(5), 212-220.

Li, B., Akintoye, A., Edwards, P. J., \& Hardcastle, C. (2005). Critical success factors for PPP/PFI projects in the UK construction industry. Construction Management and Economics 23(5), 459-471.

Li, M., \& Choi, T. Y. (2009). Triads in services outsourcing: Bridge, bridge decay and bridge transfer. Journal of Supply Chain Management 45(3), 27-39.

Lian, P. C. S., \& Laing, A. W. (2004). Public sector purchasing of health services: A comparison with private sector purchasing. Journal of Purchasing and Supply Management 10(6), 247-256.

Madhavan, R., Gnyawali, D. R., \& He, J. (2004). Two's company, three's a crowd? Triads in cooperative-competitive networks. Academy of Management Journal 47(6), 918-927.

Maxwell, J. A., \& Miller, B. A. (2008). Categorizing and connecting strategies in qualitative data analysis. In S. N. Hesse-Biber, \& P. Leavy (Eds.) Handbook of emergent methods (pp. 461477). New York: Guilford Press.

McGuire, M. (2000). Collaborative policy making and administration: The operational demands of local economic development. Economic Development Quarterly 14(3), 278-293.

Metcalf, L. E., Frear, C. R., \& Krishnan, R. (1992). Buyer-seller relationships: An application of the IMP interaction model. European Journal of Marketing 26(2), 27-46.

Parker, D., \& Hartley, K. (2003). Transaction costs, relational contracting and public private partnerships: A case study of UK defense. Journal of Purchasing and Supply Management 9(3), 97-108.

Rainey, H. G., \& Bozeman, B. (2000). Comparing public and private organizations: Empirical research and the power of a priori. Journal of Public Administration Research and Theory 10(2), 447-469.

Rees, P., \& Gardner, H. (2003). Best value, partnerships and relationship marketing in local government. International Journal of Non-profit and Voluntary Sector Marketing 8(2), 143 152.

Reijniers, J. J. A. M. (1994). Organization of public-private partnership projects: The timely prevention of pitfalls. International Journal of Project Management 12(3), 137-142.

Ring, P. S., \& Van de Ven, A. H. (1992). Structuring cooperative relationships between organizations. Strategic Management Journal 13(7), 483-498.

Roehrich, J. K., \& Caldwell, N. D. (2012). Delivering integrated solutions in the public sector: The unbundling paradox. Industrial Marketing Management 41(6), 995-1007.

Roehrich, J. K., Lewis, M. A., \& George, G. (2014). Are public-private partnerships a healthy option? A systematic literature review. Social Science and Medicine 113, 110-119.

Schaeffer, P. V., \& Loveridge, S. (2002). Toward an understanding of types of public-private cooperation. Public Performance and Management Review 26(2), 169-189. 
Simmel, G. (1950). Quantitative aspects of the group. In G. Simmel, \& K. H. Wolff (Eds.), The sociology of Georg Simmel (pp. 87-177). New York: Free Press.

Smith, J., \& Wohlstetter, P. (2006). Understanding the different faces of partnering: A typology of public-private partnerships. School Leadership and Management 26(3), 249-268.

Smyth, H., \& Edkins, A. (2007). Relationship management in the management of PFI/PPP projects in the UK. International Journal of Project Management 25(3), 232-240.

Stake, R. (2005). Qualitative case studies. In N. K. Denzin, \& Y. S. Lincoln (Eds.), Handbook of qualitative research (pp. 443-466). Thousand Oaks: Sage.

Svensson, G. (2004). Triadic trust in business networks: A conceptual model and empirical illustration. European Business Review 16(2), 165-190.

Tähtinen, J., \& Halinen-Kaila, A. (1997). The death of business triads: The dissolution process of a net of companies. Proceedings of 13th IMP Conference.

Thibaut, J. W., \& Kelley, H. H. (1959). The Social Psychology of Groups. New York: John Wiley \& Sons.

Vedel, M., Holma, A.-M., \& Havila, V. (2016). Conceptualizing inter-organizational triads. Industrial Marketing Management (in press).

Wang, S., \& Bunn, M. D. (2004). Government/business relationships: Insights into contract implementation. Journal of Public Procurement 4(1), 84-115.

Yin, R. (2003). Case study research: Design and methods. Thousand Oaks: Sage.

Zheng, J., Roehrich, J. K., \& Lewis, M. A. (2008). The dynamics of contractual and relational governance: Evidence from long-term public-private procurement arrangements. Journal of Purchasing and Supply Management 14(1), 43-54.

Zou, W., Kumaraswamy, M., Chung, J., \& Wong, J. (2014). Identifying the critical success factors for relationship management in PPP projects. International Journal of Project Management 32(2), 265-274. 